\title{
Hematospermia and xanthogranulomatous prostatitis: An unusual onset of a rare diagnosis
}

\author{
Antonio Luigi Pastore, MD; Giovanni Palleschi, MD; ${ }^{*}$ Andrea Fuschi, MD; ${ }^{*}$ Natale Porta, MD; ${ }^{+}$ \\ Bruna Cerbelli, MD; ${ }^{\dagger}$ Claudio Di Cristofano, MD; ${ }^{\dagger}$ Vincenzo Petrozza, MD; ${ }^{\dagger}$ Antonio Carbone, MD, PhD
}

\begin{abstract}
*Sapienza University of Rome, Faculty of Pharmacy and Medicine; Department of Medico-Surgical Sciences and Biotechnologies, Urology Unit - I.C.O.T, Latina, Italy; 'Sapienza University of Rome, Faculty of Pharmacy and Medicine; Department of Medico-Surgical Sciences and Biotechnologies, Urology Unit - I.C.O.T, Latina, Italy
\end{abstract}

Cite as: Can Urol Assoc J 2013;7(11-12):e820-2. http://dx.doi.org/10.5489/cuaj.1525 Published online December 5, 2013.

\section{Abstract}

Xanthogranulomatous prostatitis is a rare type of granulomatous prostatitis, with very few cases described. We report the clinical, radiological and pathological findings of 5 cases of xanthogranulomatous prostatitis. All patients came for recurrent episodes of hematospermia (associated with fever in 3 patients). All patients suffered from lower urinary tract symptoms and an increased prostate-specific antigen (PSA) level associated with a suspicious digital rectal examination (DRE); however, at biopsy, the results were negative for xanthogranulomatous prostatitis. Due to persistent severe bladder outlet obstruction, after unsuccessful medical treatments, all patients underwent transurethral resection of prostate (TURP). Final histological examination revealed a xanthogranulomatous prostatitis. The xanthogranulomatous prostatitis can be an incidental finding after TURP and it can simulate prostatic malignancy with PSA elevation.

\section{Introduction}

Granulomatous prostatitis is an unusual, non-specific inflammatory process of the prostate gland, characterized by the presence of granuloma as the main histological feature. ${ }^{1}$ It is subclassified as: infectious granuloma, nonspecific granulomatous prostatitis, post-biopsy granuloma, and systemic granulomatous prostatitis. Rare forms of granulomatous prostatitis include sarcoidosis and xanthogranulomatous prostatitis. ${ }^{2}$ This form is histologically similar to granulomatous prostatitis, with the prominence of foamy histiocytes, which constitute the xanthomatous component. Non-specific granulomatous prostatitis and xanthogranulomatous prostatitis are likely caused by a blockage of prostatic ducts and stasis of gland secretions. The resulting epithelial disruption leads to the escape of cellular debris, bacterial toxins, prostatic secretions, including corpora amylacea, sperm and semen into the stroma, determining an intense localized inflammatory response.
We present a case series of xanthogranulomatous prostatitis in 5 patients that came to our clinic between 2008 and 2011. These patients have a history of hematospermia, progressive lower urinary tract symptoms (LUTS), and increasing levels of serum prostate-specific antigen (PSA).

\section{Cases}

All patients (mean age 56.8; range: 51-62) came for recurrent episodes of hematospermia (associated with fever in 3 patients), which represented the onset symptom. All men suffered also from LUTS, characterized by urinary frequency, burning, hesitancy, and nocturia.

In all patients, a PSA elevation was observed (range: 4.8$6.7 \mathrm{ng} / \mathrm{mL}$ ), with a normal ratio always greater than $20 \%$ (range: $22-36 \%$ ). ${ }^{3}$ Digital rectal examination (DRE) revealed an increase in the gland size and a change in the consistency with an irregular surface in all cases. The palpatory findings (peripheral nodule of hard consistency) and the serum PSA level ( $>4 \mathrm{ng} / \mathrm{mL}$ ) also confirmed the use of antibiotic therapy and this lead us to suspect malignancy in all cases. As such, the patients had an ultrasound-guided transperineal prostatic biopsy (12 cores) to exclude a malignant diagnosis.

All patients were then treated for LUTS with medical therapy (alpha-adrenergic blockers plus Serenoa repens), but none reported any significant symptom improvement (evaluated by International Prostate Symptom Score [IPSS] self-administered questionnaire or the objective clinical instrumental parameters [uroflowmetry and post-voiding residual]). For this reason all the subjects were evaluated by transrectal ultrasound examination (TRUS) and urodynamics. TRUS showed a marked inhomogeneity of prostate tissue, with several hypoechoic and hypervascularized areas and calcifications along the peripheral surface of the adenoma, while pressure/flow studies showed the presence of a severe bladder outlet obstruction (BOO). Therefore, all patients underwent transurethral bipolar endoscopic resection of the prostate (TURP). During surgery, the prostate gland tissue appeared white-yellowish and presented no histiocytes significant bleeding. After super- 
ficial resection, minimal pus came out from small, occasional abscess pockets. No intra- or postoperative complications occurred. The mean catheterization time was 3 days; one patient had acute urinary retention 48 hours after catheter removal due to inflammatory condition, revealed by DRE. PSA levels significantly decreased and were below $2 \mathrm{ng} / \mathrm{mL}$ in all patients. Urinary urgency and burning were the most represented urinary symptoms during the first 2 weeks after surgery; 2 patients required additional antibiotic and antiinflammatory medication. All patients achieved normal IPSS scores and normal uroflowmetry parameters 5 weeks after surgery. Histopathological examination of resected prostatic tissue in all patients revealed xanthogranulomatous prostatitis with no evidence of malignancy. A non-specific granuloma- tous inflammation was found, mainly consisting of plasma cells, lymphocytes, neutrophils, eosinophils, multinucleated giant cells, and epithelioid cells that surrounded, distended or destroyed glandular lumens. The granulomas were composed of multinucleated giant cells and "xanthogranulomatous cells" (diffusely in 4 cases, focally in the fifth). Xanthomatous histiocytes presented a small dark nuclei and abundant clear to foamy cytoplasm due to fat droplets and could be confused with prostate carcinoma (Fig. 1, part A and B). ${ }^{4}$ The aggregate macrophages were positive for CD68 immunostaining (Fig. 1, part E), ${ }^{5}$ which stained tissue histiocytes and macrophages, and were negative for CD3 and CD20, which stained lymphoid mixed infiltrate (CD3 for lymphocytes $\mathrm{T}$ and CD20 for lymphocytes B). CD34 showed diffuse neo-

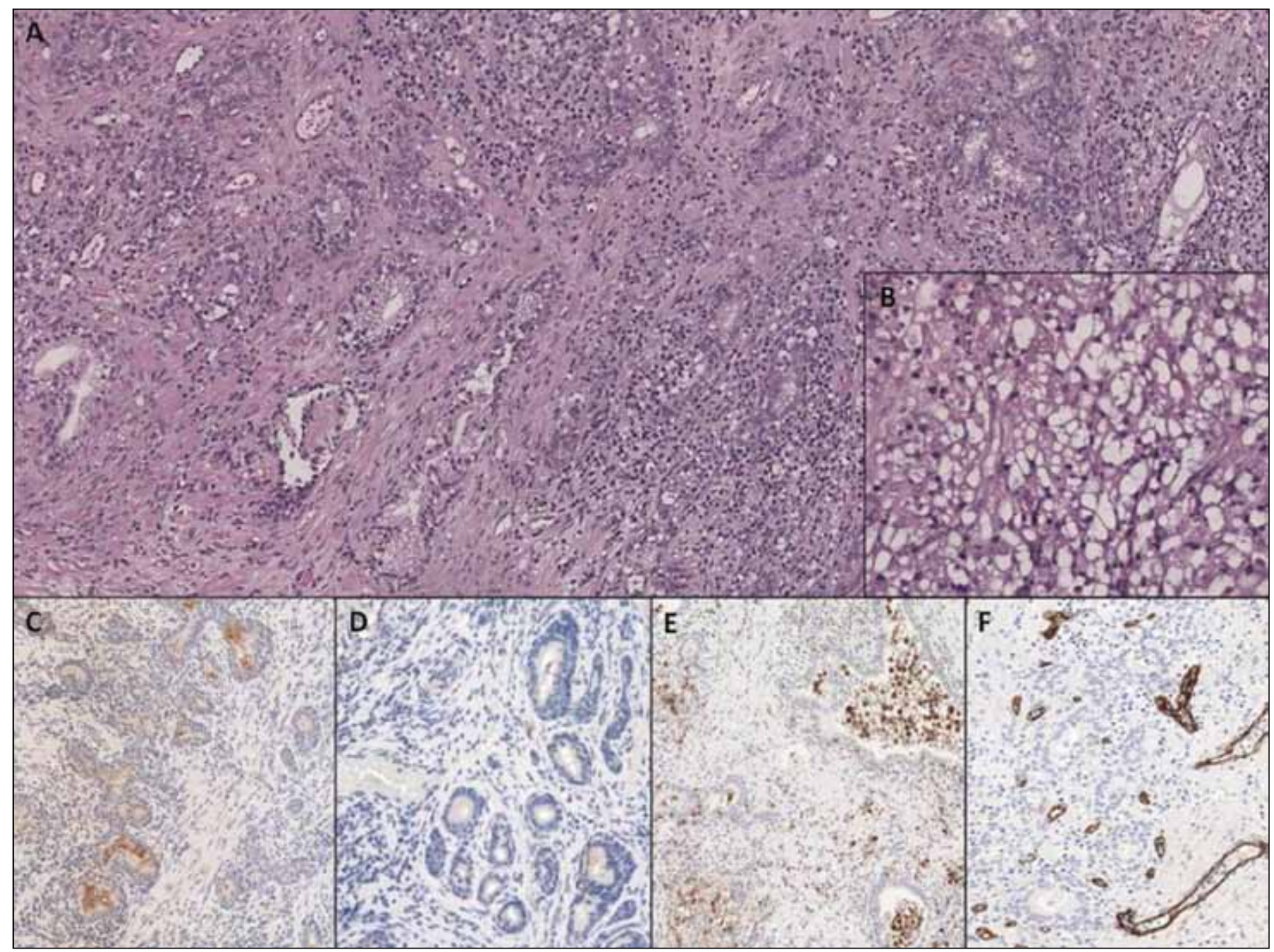

Fig. 1. (A) Low-power photomicrograph showing intense inflammatory infiltrate in prostatic tissue, composed of lymphocytes, plasma cells, neutrophils and xanthogranulomatous cells (magnification 10x); (B) High-power photomicrograph showing xanthomatous histiocytes, characterized by small dark nuclei and abundant clear to foamy cytoplasm (magnification 40x); (C) Prostate-specific antigen stain showing the presence of normal prostate gland inside and near the inflammatory reaction (magnification 10x); (D) Negativity of prostate glands for alpha-methylacyl-CoA racemase stain is indicative of absence of carcinoma (magnification 10x); (E) CD68 stain showing the presence of xanthomatous histiocytes inside the lumen of the glands and in the prostatic stroma (magnification 10x); (F) CD34 stain showing neoangiogenesis secondary to the acute inflammatory process (magnification 10x). 
angiogenesis inside the inflammatory reaction (Fig. 1, part F), because CD34 is a specific marker of endothelial cells. PSA showed some small non-neoplastic glands close to the granulomatous reaction (Fig. 1, part C), that were negative for alpha-methylacyl-CoA racemase (Fig. 1, part D). ZiehlNeelsen stain for acid fast bacilli was negative in all 5 cases. Corpora amylacea were also present.

\section{Discussion}

Xanthogthranulomatous prostatitis is an unusual benign inflammatory process of the prostate gland, first described by Tanner and Mc Donald in $1943 .{ }^{6}$ It is a rare subtype of granulomatous prostatitis, sometimes associated with hyperlipidemia. The etiology and pathogenesis are unclear, although some authors suggest a role of glandular ducts obstruction in its pathogenesis. ${ }^{7}$ On average, patients usually present around age 60; the range can be from patients in their twenties to the very elderly.

The granulomatous prostatitis, and its rare variant xanthogranulomatous, are poorly defined clinically and features may include irritative LUTS, frequency and burning, pyuria and hematuria sometimes combined with hematospermia. ${ }^{8}$ In $20 \%$ of cases, granulomatous prostatitis presents with a triad of sudden-onset high fever, symptoms of prostatitis and a nodular painless firm with a prostate enlargement, palpable on DRE. ${ }^{9}$ However, as our case series revealed, most patients suffer from a severe $\mathrm{BOO}$, which might exacerbate the chronic inflammatory condition of the prostate; this can help determine the xanthomatous phenomenon inside the gland. According to this hypothesis, as expected, in our case series the complete symptoms relief was achieved only through surgery.

Hematospermia as the onset symptom has not been reported so far. Hemospermia has been sporadically reported as an accompanying symptom in very few cases, ${ }^{10}$ but only in our case series it represented the uncommon symptom of disease onset. In $40 \%$ of all cases reporting hematospermia, an infectious condition is revealed. Other etiologic factors are inflammatory conditions, neoplasms and iatrogenic factors. After confirming the presence of hematospermia, physicians should perform a clinical evaluation, including clinical history and physical examination with DRE.

A PSA level increase is often observed, with a reported rise to $150 \mathrm{ng} / \mathrm{mL}$ in 1 case. On rectal examination, the prostate may be hard and nodular mimicking prostate carcinoma, which must be excluded. ${ }^{4,11}$ The transrectal ultrasound and magnetic resonance image cannot distinguish this entity from prostatic malignancy, but generally the ultrasound shows hypoechoic lesions. ${ }^{12}$ The final diagnosis can only be achieved by histopathological examination of the prostate. The histological feature of xanthogranulomatous prostatitis is the presence of macrophages with foamy cytoplasm "xanthomatous cells" (CD68+) in the mixed flogistic infiltrate with multinucleated giant cells.
In our case series, the hematospermia was always the onset symptom, which was accompanied by severe LUTS secondary to BOO. The histopathologic findings after performing TRUS-guided transperineal biopsy only revealed a non-specific inflammatory process of the peripheral gland. The patients were non-responsive to combined medical therapy, so TURP was performed in all cases.

\section{Conclusion}

To diagnose the xanthogranulomatous prostatitis, we highlight the importance of histological findings obtained on the specimen of the transitional zone after performing TURP. In addition, the immunohistochemical examination, such as CD68 and PSA, were crucial in getting a definitive diagnosis and in excluding the presence of carcinomatous foci that may be suspected.

Competing interests: Dr. Pastore, Dr. Palleschi, Dr. Fuschi, Dr. Porta, Dr. Cerbelli, Dr. Di Cristofano, Dr. Petrozza and Dr. Carbone all declare no competing financial or personal interests.

This paper has been peer-reviewed.

\section{References}

1. Epstein JI, Hutchins GM. Granulomatous prostatitis: Distinction among allergic, nonspecific, and posttransurethral resection lesions. Hum Pathol 1984;15:818-25. http://dx.doi.org/10.1016/S0046$8177(84) 80142-2$

2. Shanggar K, Zulkinfli MZ, Razack AH, et al. Granulomatous prostatitis: A reminder to clinicians. Med J Malaysia 2010;65:21-2.

3. Speights V0 Jr, Brawn PN. Serum prostate-specific antigen levels in non-specific granulomatous prostatitis. Br J Urol 1996;77:408-10. http://dx.doi.org/10.1046/i.1464-410X.1996.89315.x

4. Srigley JR. Benign mimickers of prostatitic adenocarcinoma. Mod Pathol 2004;17:328-48. http://dx.doi. org/10.1038/modpathol.3800055

5. Mbakop A, Reverdin N, Cox JN. Nonspecific granulomatous prostatitis. Histopathological study of 53 cases with a review of the literature. Schweiz Med Wochenschr 1985;115:522-5.

6. Tanner FH, McDonald JR. Granulomatous prostatitis: A histologic study of a group of granulomatous lesions collected from prostate glands. Arch Pathol 1943;36:358-70.

7. Sebok J, Fuzesi L, Loth J, et al. A contribution to the pathology and clinical features of granulomatous prostatitis. Int Urol Nephrol 1982;14:45-50. http://dx.doi.org/10.1007/BF02082382

8. Stillwell TJ, Engen DE, Farrow GM. The clinical spectrum of granulomatous prostatitis: a report of 200 cases. J Urol 1987;138:320-3.

9. Uzoh CC, Uff JS, Okeke AA. Granulomatous prostatitis. BJU Int 2007;99:510-2. http://dx.doi. org/10.1111/i.1464-410X.2006.06585.x

10. Razek AA, Elhanbly S, Eldeak A. Transrectal ultrasound in patients with hematospermia. J Ultrasound 2010;13:28-33. http://dx.doi.org/10.1016/i.jus.2009.09.005

11. Rafique M, Yaqoob N. Xanthogranulomatous prostatitis: A mimic of carcinoma of prostate. World I Surg Oncol 2006;4:30. http://dx.doi.org/10.1186/1477-7819-4-30

12. Lee HY, Kuo YT, Tsai SY, et al. Xanthogranulomatous prostatitis: a rare entity resembling prostate adenocarcinoma with magnetic resonance image picture. Clin Imaging 2012;36:858-60. http://dx.doi. org/10.1016/i.clinimag.2012.01.034

Correspondence: Dr. Antonio Luigi Pastore, Department of Medical and Surgical Sciences and Biotechnologies, Unit of Urology, Faculty of Pharmacy and Medicine, Sapienza University of Rome, Corso della Repubblica 79, 04100 Latina (LT), Italy; antopasł@hotmail.com 